\title{
Polymer Nanocomposite: A Promising Flame Retardant
}

\section{Qingsheng Wang*}

\author{
Department of Chemical Engineering and Department of Fire Protection \& Safety, Oklahoma State University, USA
}

*Corresponding author: Qingsheng Wang, Assistant Professor, Department of Chemical Engineering and Department of Fire Protection \& Safety, Director, Boots \& Coots Center for Fire Safety and Pressure Control, Oklahoma State University, Stillwater, OK 74078, USA, Fax: +1-405-744-6758, Tel: +1-405-744-5508, E-mail: qingsheng.wang@okstate.edu

\section{Citation: Qingsheng Wang (2013) Polymer Nanocomposite: A Promising Flame Retardant. J Mater Sci Nanotechnol 1(2): e202. doi: 10.15744/2348-9812.1.e202}

Received Date: October 24, 2013 Accepted Date: October 28, 2013 Published Date: October 30, 2013

Fire has long been a major hazard in our lives. From the fire protection engineering point of view, most fire hazards could be controlled when we consider all contribution factors, such as ignitability, flame spread, materials flammability, and fire suppression [1]. According to the 2011 statistics data from the National Fire Protection Association (NFPA), 35\% of the fires that occurred in the US were structure fires, of which $84 \%$ were homes and most of the people died due to inhalation of smoke [2]. Polymeric materials have been used almost everywhere in buildings, manufacturing, housing, and vehicles but most of these materials are highly combustible and produce toxic fumes on burning. When it is used as films, coatings and foams, those thin objects are even more combustible than bulk materials. All polymer fires start with an ignition event and they are burn by producing gas phase fuels which combine with air and sustain the fire until the entire polymer is gone [3].

To control those polymer fires, flame retardant technology is becoming increasingly important [4]. In general, flame retardant additives are used to limit the fire risk. Those additives are incorporated in the polymer matrix to increase the time to ignition, improve self-extinguishing properties, decrease the heat release rate and prevent the formation of flammable drops. Although flame retardants may differ from one another, three general flame retardancy mechanisms are applicable: gas phase flame retardants, endothermic flame retardants, and char-forming flame retardants $[5,6]$.

I. Gas phase flame retardants (i.e., halogen, phosphorus): This is the chemical mechanism in the gas phase. These materials reduce the heat released in the gas phase from combustion by scavenging free radicals.

II. Endothermic flame retardants (i.e., metal hydroxides, carbonates): This is the physical mechanism in the gas phase. When on fire, these materials release a large amount of nonflammable gases $\left(\mathrm{H}_{2} \mathrm{O}, \mathrm{CO}_{2}\right)$, which dilute flammable gas and decease the temperature.
III. Char-forming flame retardants (i.e., intumescents, nanocomposites): This is the condensed phase mechanism. These materials operate by preventing fuel release through binding up fuel as non-pyrolyzable carbon (char) and providing thermal insulation for underlying polymer through the formation of char protection layers.

Most traditional flame retardants like halogenated organics have been limited in their utility due to health and environmental concerns and other fire retardants like aluminum hydrates are expensive and need to be used in large quantities which make the polymer lose its original properties (i.e., mechanical properties) [6,7]. Recently, flame retardant polymer nanocomposites have gained popularity and have made tremendous progress [8]. The detail understanding of the char-forming mechanism is the key to develop a new type of flame retardant. The combustion behavior of polymer nanocomposites is due to a two fold mechanism brought by nanofillers: a physical barrier effect and a chemical charring catalytic action occurring in the condensed phase [9]. Flame retardant nanofillers like clays [10], metal oxide nanoparticles [11], carbon nanotubes [12], when added to the polymers, operate typically in the condensed phase by forming a surface layer which limits the supply of the polymer to the fire.

It is noted that not only nanofillers are important for the formation of a physical barrier in the condensed phase but there is also a need for catalysts that can change the degradation pathway of the polymer. In order to achieve higher fire performance levels, it is necessary to develop a flame retardant system based on a combination of different flame retardant agents. Most of current research focuses on the thermal stability of the polymer nanocomposites and the composition of the char formed to show the synergistic effects towards improved fire retardancy. However, in depth understanding of the degradation mechanism and the quantification of the synergistic effects are very limited. It is imperative to develop physical models to quantify the synergistic effects using heat and mass transfer principles. Polymer nanocomposites have made great stride and we should expect to see more 
commercial products utilizing this technology in the future. More and more new flame retardant polymer nanocomposites will be developed to improve fire safety for society.

\section{Acknowledgement}

Qingsheng Wang gratefully acknowledges financial support from Oklahoma State University and the National Science Foundation (CBET-1336254, CBET-1336162).

\section{References}

1. Quintiere JQ (1997) Principles of Fire Behavior. Delmar Publishers, New York, United States.

2. National Fire Protection Association.

3. Mouritz AP, Gibson A G (2006) Fire Properties of Polymer Composite Materials. Springer, New York, United States.

4. Bellucci F, Camino G, Nicolais L (2012) Flammability of Polymer Composites. Wiley Encyclopedia of Composites, John Wiley \& Sons, Inc., New Jersey, United States.
7. Betts KS (2008) New thinking on flame retardants. Environ Health Perspect 116: A210-3.

8. Morgan AB, Wilkie CA (2007) Flame retardant polymer nanocomposites. John Wiley \& Sons, Inc., New Jersey, United States.

9. Duquesne S, Magniez C, Camino G, Castrovinci A, Camino G (2007) Multifunctional Barriers for Flexible Structure: Fire-retardant mechanisms in polymer nano-composite materials. Springer, New York, United States.

10. Pavlidou S, Papaspyrides CD (2008) A review on polymer-layered silicate nanocomposites. Prog Polym Sci 33: 1119-98.

11. Friederich B, Laachachi A, Ferriol M, Ruch D, Cochez M, et al.(2010) Tentative links between thermal diffusivity and fire-retardant properties in poly(methyl methacrylate)-metal oxide nanocomposites. Polym Degrad Stab 95: 1183-93.

12. Kashiwagi T, Du F, Winey KI, Groth KM, Shields JR, et al. (2005) Flammability properties of polymer nanocomposites with single-walled carbon nanotubes: effects of nanotube dispersion and concentration. Polymer 46: 471-81.

5. Bourbigot S, Bras ML (2003) Flammability Handbook: Fire Retardant Plastics. Hanser Publications, Munich, Germany.

6. Morgan AB, Gilman JW (2013) An overview of flame retardancy of polymeric materials: application, technology, and future directions. Fire and Materials 37: 259-279.

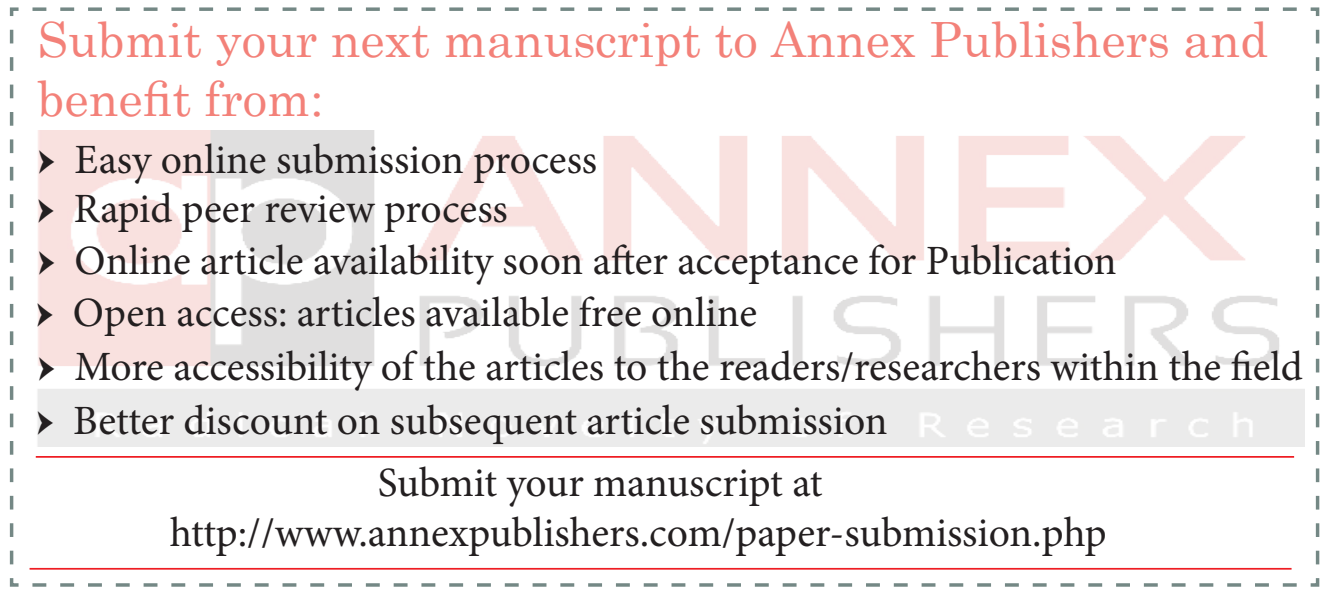

